\title{
Pemanfaatan Sigil Untuk Pembuatan E-Book (Electronic Book) dengan Format EPub
}

\author{
Rahmat Hidayat ${ }^{1, *}$, Erwadi $^{2}$, Vitria Ratna Sari³ ${ }^{3}$ Vide Rawi Purnama Ade ${ }^{4}$ \\ 1,2 Jurusan Teknologi Informasi, Politeknik Negeri Padang \\ 3,4 STEI, Institut Teknologi Bandung \\ (corresponding author) rahmat@polinpdg.ac.id*
}

\begin{abstract}
Being a collector of book collection from past millions of years will cost a lot of money to preserve, on the other hand an increasing number of authors that publish their work will also a grew up room space for storing books. By using technology, there is a new format of that known as an electronic book (e-book). E-books can be read by using computers, laptops and even mobile devices. A wide variety of e-book format has been used but only e-pub can suitable for various screen size of mobile devices. Then e-pub is a standard format that have been introduced by Intenational Digital Publishing Forum (IDPF) on October, 2011 with SIGIL as an application editor. Sigil is an Open Source editor that available for all writers and readers.
\end{abstract}

Keyword- Electronics Book, E-Book, Epub, Sigil

Intisari-Memiliki koleksi buku yang berusia jutaan tahun akan membutuhkan biaya yang besar untuk merawatnya selain itu semakin banyaknya penulis menerbitkan buku-bukunya semakin banyak juga ruangan yang disediakan untuk menyimpan buku-buku tersebut. Dengan berkembangnya dunia teknologi, sekarang sudah ada buku digital atau lebih dikenal dengan elektronik book (e-book). E-book dapat dibaca dengan perangkat komputer, laptop bahkan perangkat seluler. Berbagai macam format e-book yang telah digunakan namun yang dapat menampilkan e-book sesuai dengan perangkat seluler dengan ukuran layar yang bervariasi adalah format electronic publication (epub). Jadi epub adalah standar format e-boook yang diperkenalkan oleh Intenational Digital Publishing Forum (IDPF) pada oktober 2011 dengan aplikasi editornya sigil. Sigil adalah sebuah editor Open Source yang mudah didapatkan oleh semua penulis maupun pembaca.

Kata Kunci-Electronic Book, E-Book, Epub, Sigil

\section{PENDAHULUAN}

Koleksi buku yang berusia jutaan tahun mengalami degradasi kualitas cetakan sehingga terjadi pelapukan kertas yang mengakibatkan buku rusak bahkan bisa habis dimakan rayap. Jika buku tersebut rusak, maka akar sejarah perjalanan dari suatu bangsa akan hilang dimakan masa. Untuk mengurangi biaya perawatan buku dan menghemat sumber daya alam seperti pemakaian kertas agar tidak tejadinya pengundulan hutan dan perusakan hutan, pembuatan buku digital menjadi salah satu solusinya.

Buku digital atau lebih sering dikenal dengan e-book didefenisikan oleh kamus bahasa inggris Oxford yaitu "buku dalam bentuk digital yang terdiri dari teks, gambar atau keduanya, dan diproduksikan pada, dipublikasikan melalui dan dibaca di kompuer atau perangkat komputer lainnya".[1]. Jadi buku digital merupakan sebuah publikasi yang terdiri dari teks, gambar dan dapat diakses melalui perangkat komputer atau telepon seluler dan perangkat elektronik yang lainnya.

Dengan hadirnya E-book ini dapat mempermudah para pembaca dan para penulis dalam mengkoleksi serta menyebarkan buku-bukunya, karena para penulis tidak perlu lagi datang ke penerbit untuk menerbitkan buku yang ditulis. Penulis dapat menjual atau mempublikasikan tulisannya melalui e-book, hal serupa dapat digunakan oleh para pembaca dan pencari ilmu di internet [2].

Beberapa tahun terakhir ini minat pembaca e-book secara signifikan berkembang. Dua format dokumen utama yang didukung oleh sebagian besar perangkat adalah PDF dan electronic publication (epub). Format PDF secara luas digunakan untuk berbagi dokumen memungkinkan pembacaan cross-platform. Namun format PDF ini membuat pembaca merasa tidak nyaman karena ukuran layar perangkat yang kecil. Pada sebaliknya, format epub adalah re-flowable dan cocok untuk pembaca e-book dengan segala jenis ukuran layar perangkat [3].

Epub merupakan format standar digital book yang diperkenalkan oleh Intenational Digital Publishing Forum (IDPF) [4]. 
Format epub dapat dibaca di berbagai perangkat seperti komputer (AZARDI, Calbre, plugin firefox, plugin google chrome), Android (FBReader, Ideal Reader), iOS (ireader), Kobo eReader, Blackberry playbook, Barnes and Noble Nook, Sony Reader dan berbagai perangkat lainnya [5].

Ada beberapa aplikasi yang menyusun e-book yang berformat Epub. Salah satunya adalah Sigil. Sigil merupakan sebuah software editor yang Open Source, sigil dapat di download pada website https://code.google.com/p/sigil/.

\section{Metodologl}

Pertimbangan memilih Epub sebagai format digital book adalah (1) jumlah ketersediaan perangkat pendukung yang ada di indonesia. Jumlah pengguna perangkat seluler belum tentu semuanya smartphone, featurephone ataupun bisa digunakan sebagai modem; (2)Ukuran tampilan aplikasi pembaca digital book, format PDF tidak akan menjadi masalah apabila dibaca menggunakan komputer atau laptop, namun akan ditujukan kepada perangkat seluler lainnya yang memiliki ukuran layar yang bervariasi, maka diperlukan format buku digital yang dapat menyesuaikan denngan tampilan layar; (3) Format yang didukung secara luas. Format yang mendapat dukungan secara luas untuk pembuatan buku digital maupun aplikasi pembacanya adalah Epub. Pada Epub versi 3.0 telah menyertakan fitur audio, video bahkan animasi di dalam buku digital. [5]

Beberapa fitur sigil adalah gratis dan Open Source dengan lisensi GLPv3, multiplatform (dapat dijalankan di Windows, Linux dan Mac), multiple view (book view, code view dan preview), dapat langsung mengedit Epub langsung pada book view, generator daftar isi dengan support untuk heading multi-level, editor metadata.

Sigil versi 0.7.0 sudah didukung dengan import video dan audio dalam pembuatan e-book kali ini sigil yang digunakan versi 0.7.2.

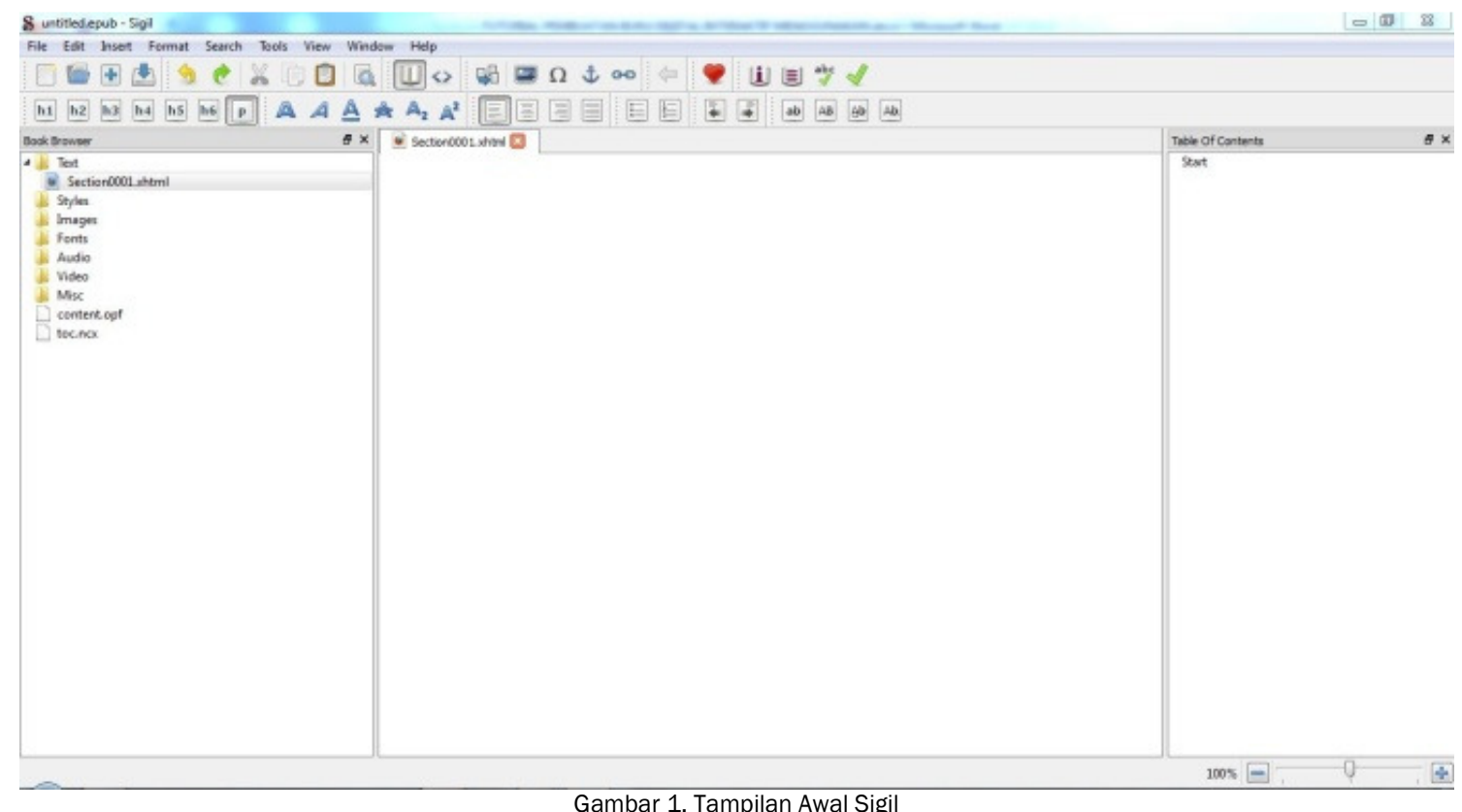

Dari gambar 1. Tampilan awal sigil, panel sebelah kiri berfungsi untuk mencari file-file yang akan di Epub-kan dan file yang ada dalam Epub, panel tengah berfungsi sebagai editor dan panel sebelah kanan berfungsi untuk daftar isi dari dokumen Epub yang dikerjakan.

Dalam pembuatan e-book hal yang harus diperhatikan adalah persiapan materi, dalam persiapan materi perlu diperhatikan bagaimana pembaca dapat diberi kebebasan mengakses isi buku dengan cara tidak runtun atau bab per bab dan memperhatikan target perangkat yang akan digunakan oleh pembaca. Karena mengingat pembaca menggunakan fiture phone, tidak semua handphone pembaca yang dapat mengakses Epub disertai video dan audio, adapun pembaca yang ingin menampilkan Epub disertakan video dan audio atau sebaliknya hanya menampilkan teks dan gambarnya saja. Sehingga pada proses pembuatan e-book setidaknya menyiapkan dua versi yaitu e-book disertai multimedia (video dan audio) dan e-book yang berisi teks dan gambar.

Pembuatan e-book pada sigil ada dua cara yaitu dengan cara merubah dokumen yang berktensi .doc/.docx menjadi ekstensi atau save as dengan ekstensi .html. Dengan cara Save As >> Web Page, Filtered (*.htm; *.html) (Save as type) >> Save seperti gambar 2 dibawah ini. 


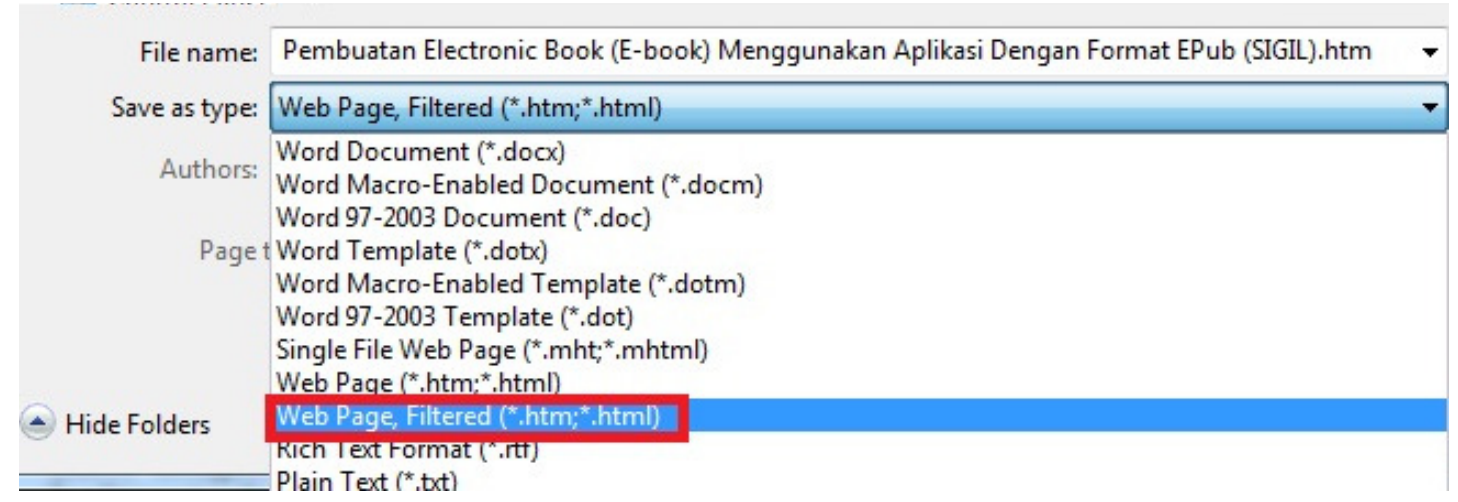

Gambar 2. Tampilan konverter dari doc ke html

Setelah file berekstensi .html, buka file tersebut pada sigil dengan cara File $>>$ Add $>>$ Existing Files.... Dan hasilnya seperti gambar 3 dibawah ini.

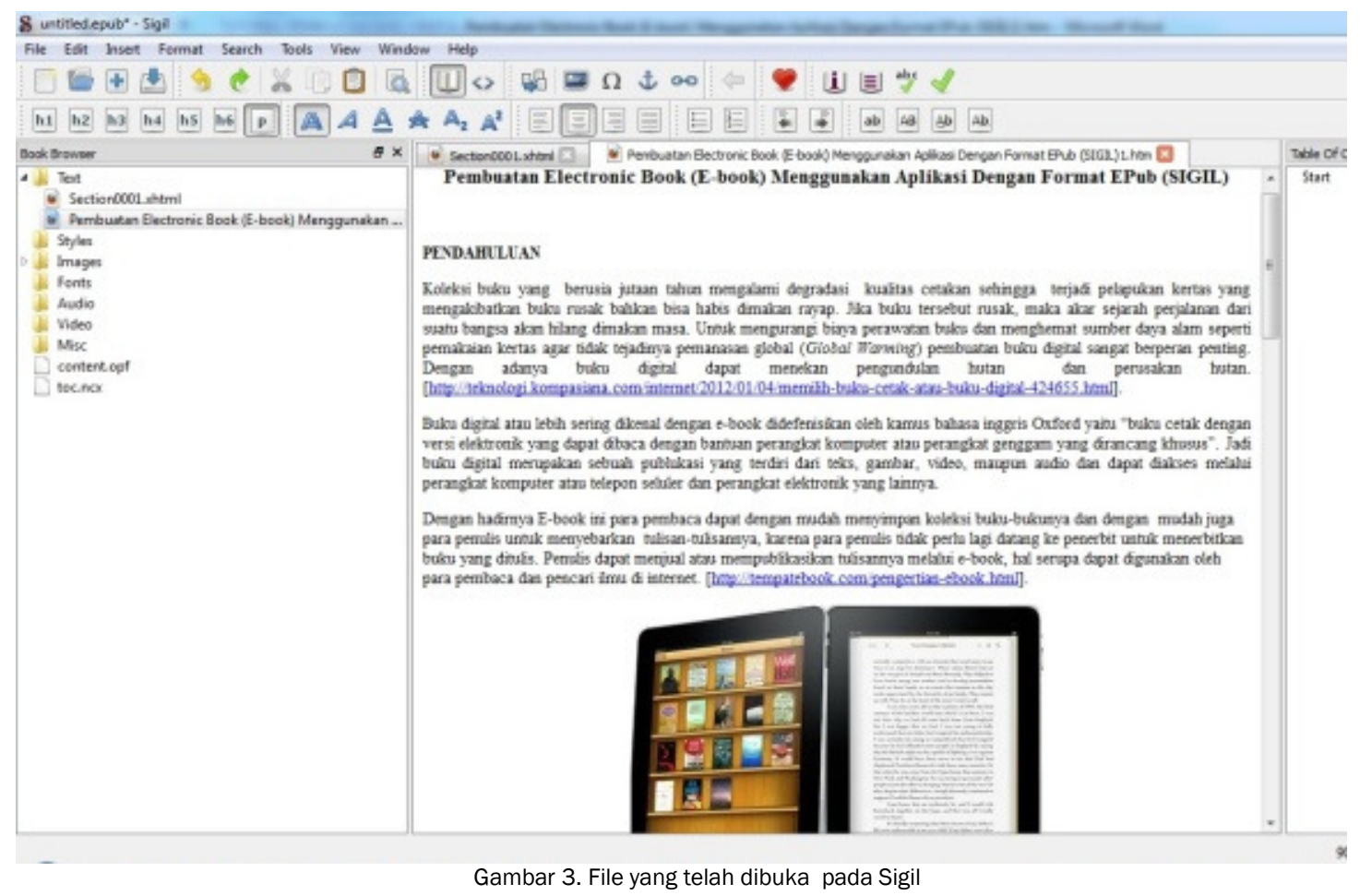

Perhatikan file yang telah dibuka pada sigil, pastikan tidak ada kesalahan penulisan atau kelebihan spasi maupun tata letak gambar dan tabel. Setelah dirasa semua penulisan benar tambahkan keterangan file atau buku yang di digitalisasikan ini pada metadata editor seperti pada gambar 4. Metadata editor berfungsi menabahkan identitas buku misalnya : judul,nama pengarang, tahun penerbitan, bahasa ISBN, penerbit, kategori, deskripsi, dan lain-lain. 


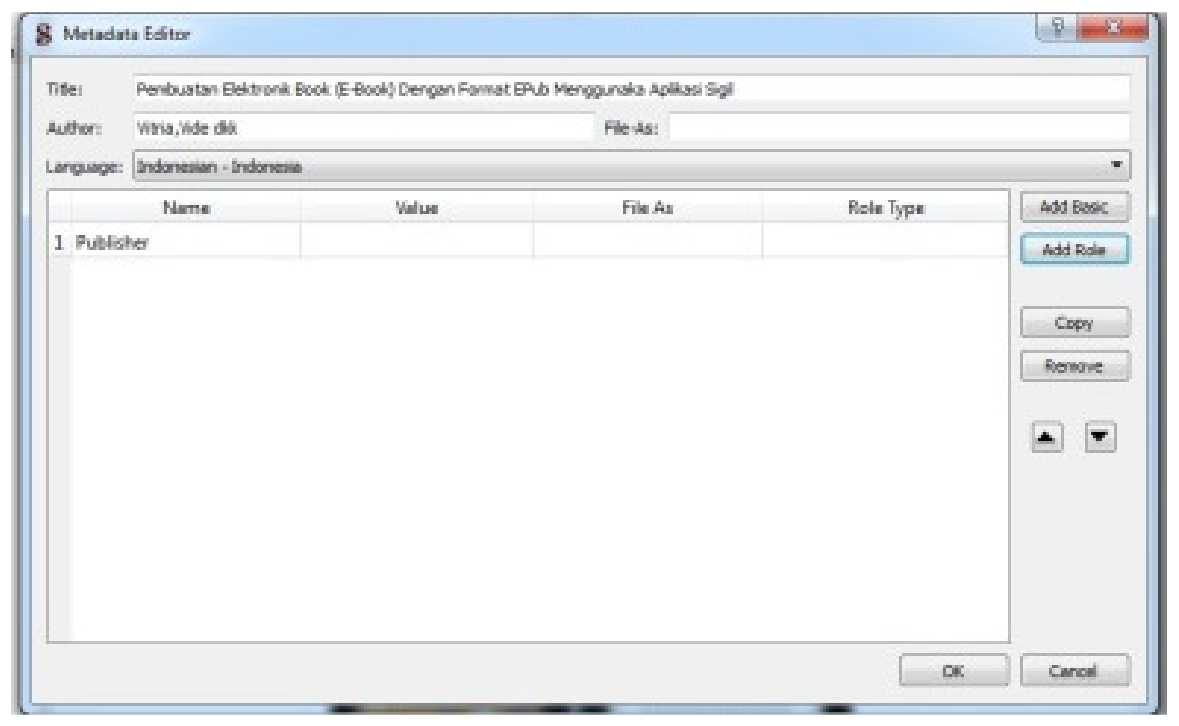

Gambar 4. Tampilan Jendela Metadata editor

Cara kedua pembuatan e-book dengan aplikasi sigil adalah merubah file dokumen menjadi image, pengubahan dokumen menjadi image dapat menggunakan Nitro Pro 7 dengan tampilan seperti gambar 5.

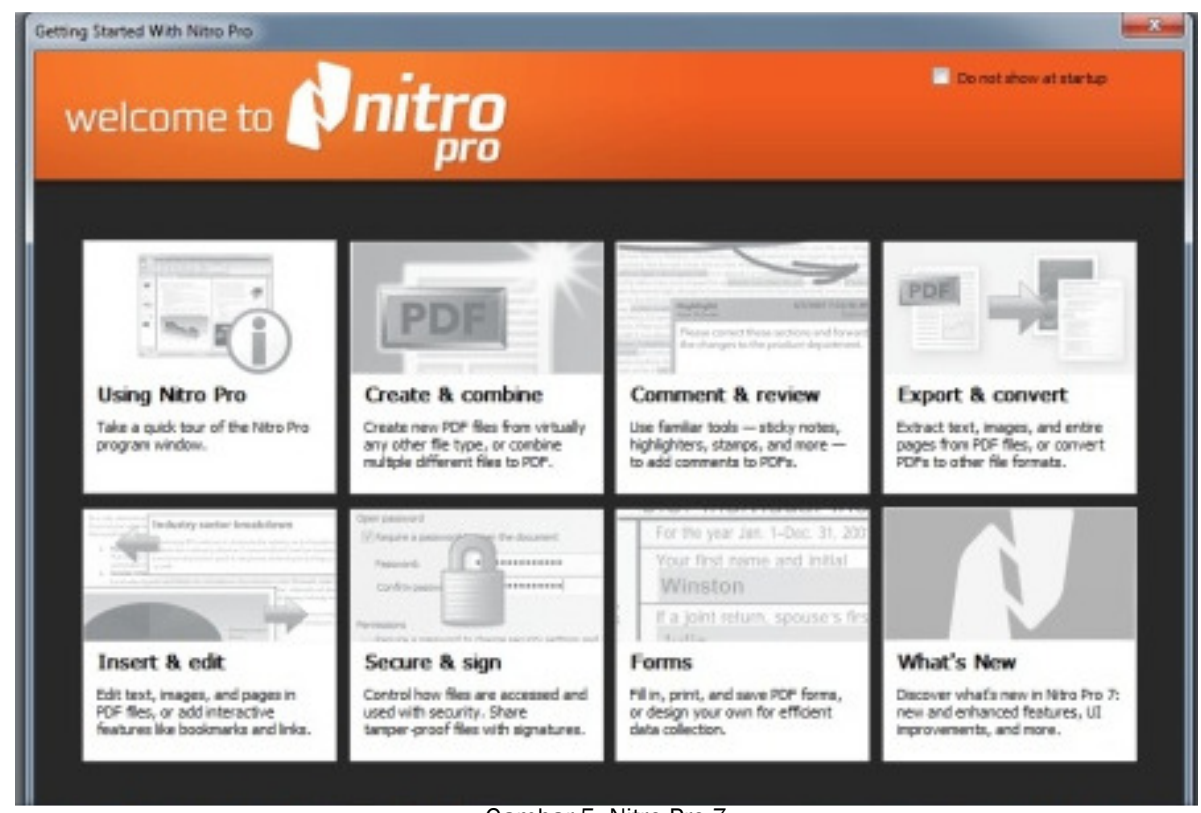

Gambar 5. Nitro Pro 7

Cara kedua ini sangat mudah digunakan dan tampilannya sama seperti yang dibuat oleh penulis. File dokumen yang dirubah ke image sebelumnya dirubah dulu ke pdfsetelah itu baru bisa di rubah menhjadi image. Buka sigil dan insert file seperti gambar 6 untuk di susun menjadi sebuah buku digital. 


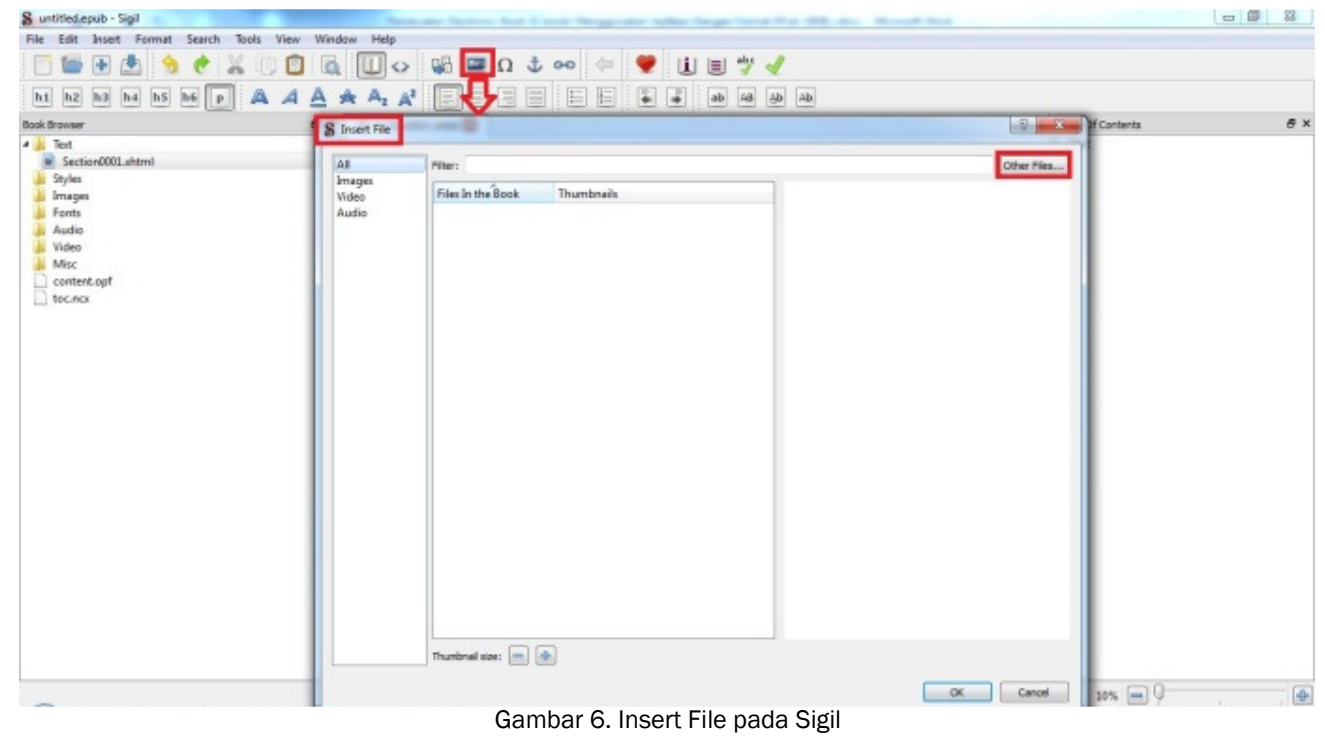

Cara ini mempunyai kekurangan yaitu jika terjadi perubahan pada isi buku, maka harus melewati proses yang sama pada saat pertama kali membuat e-book.

Selanjutnya membuat cover buku dengan cara klik Tools >> Add cover > $>$ dan pilih file yang akan dijadikan cover buku seperti gambar 7 dibawah ini.

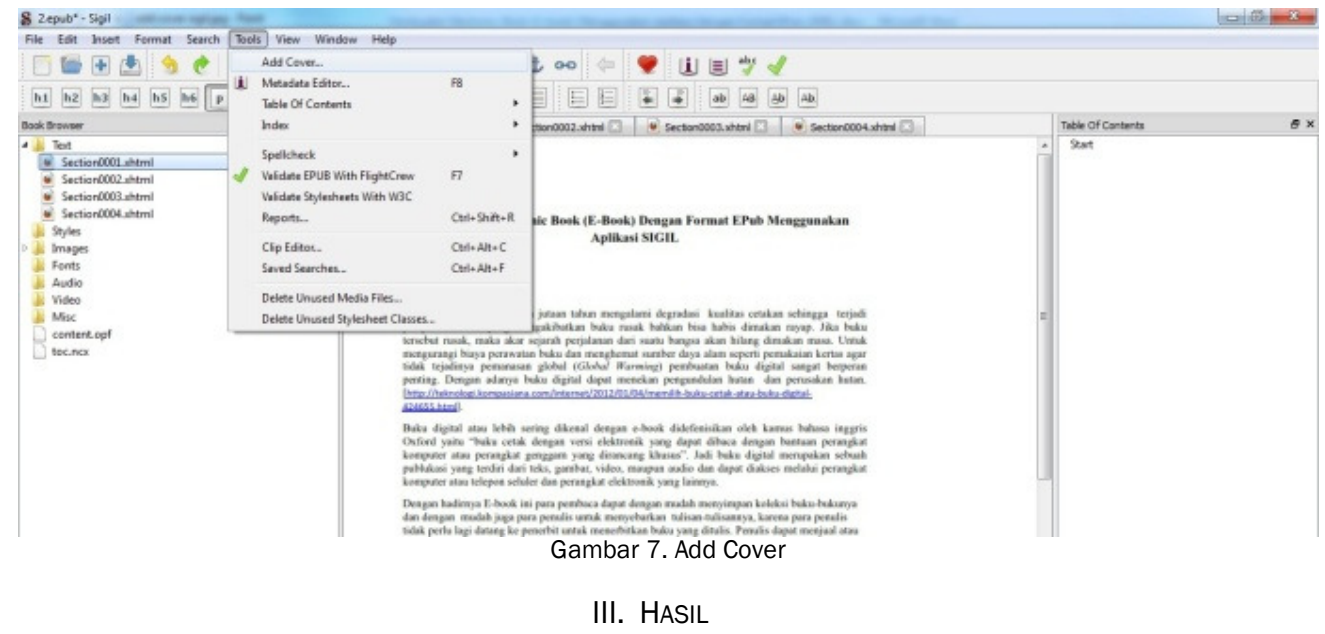

E-book yang dibuat melalui aplikasi sigil bisa ditampilkan di redium pada google chrome, hasil e-book tersebut seperti gambar 8, menampilkan halaman readium yang memperlihatkan e-book dan gambar 9 menampilkan isi dari e-book. 


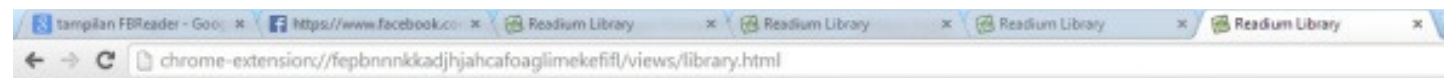

\section{Readium .}

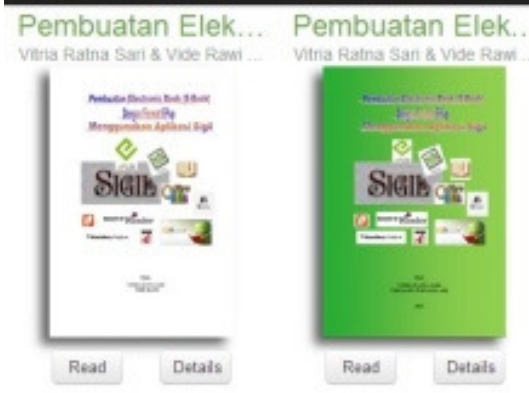

Gambar 8. Tampilan kumpulan e-book di readium

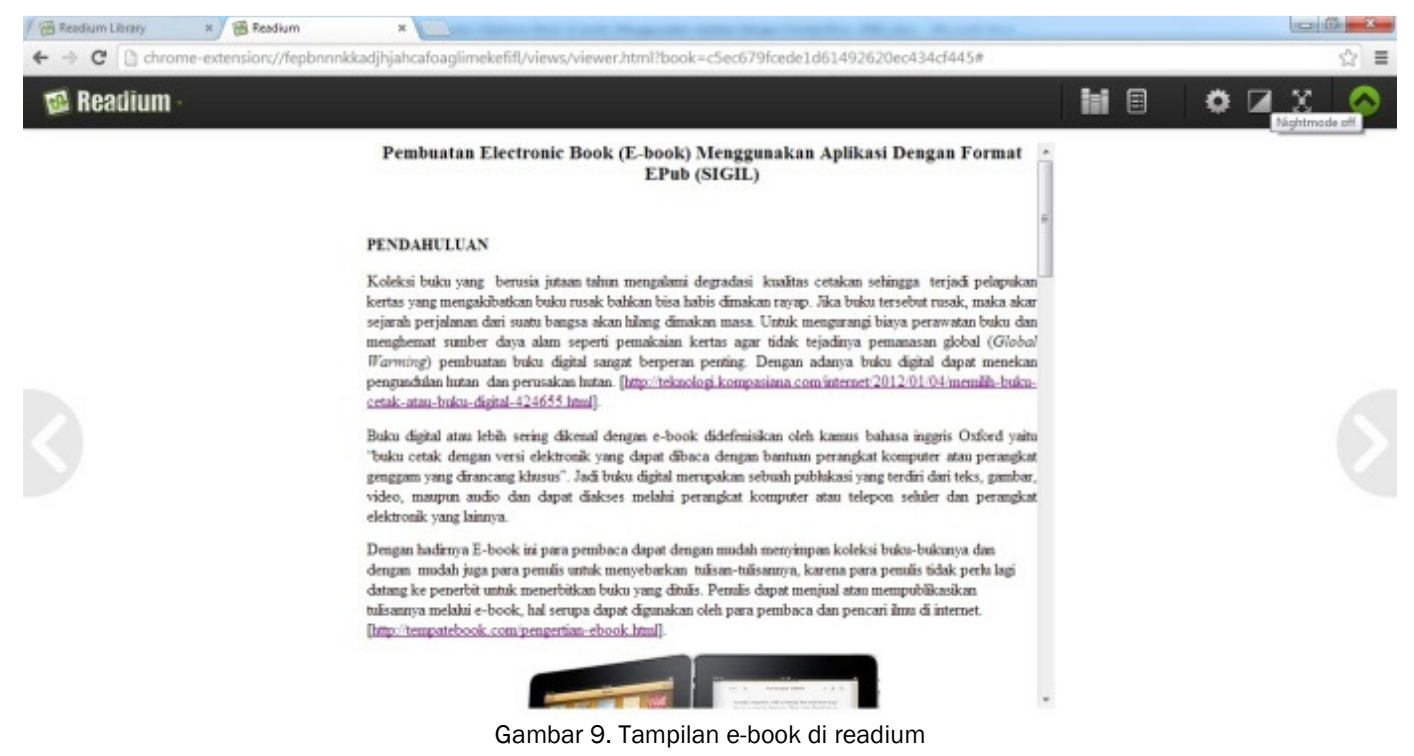

Tampilan e-book pada kobo ereader seperti gambar 10 dan gambar 11 merupakan tampilan e-book pada tablet.
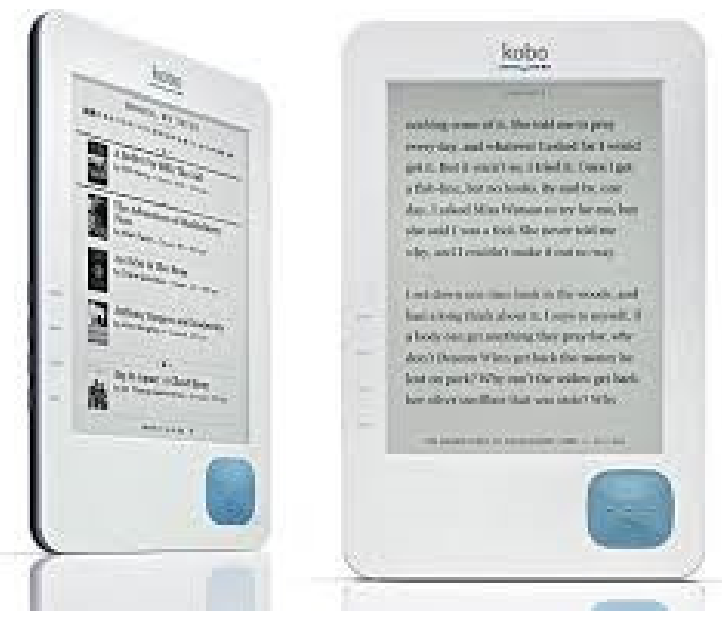

Gambar 10. Tampilan e-book di Kobo eReader 


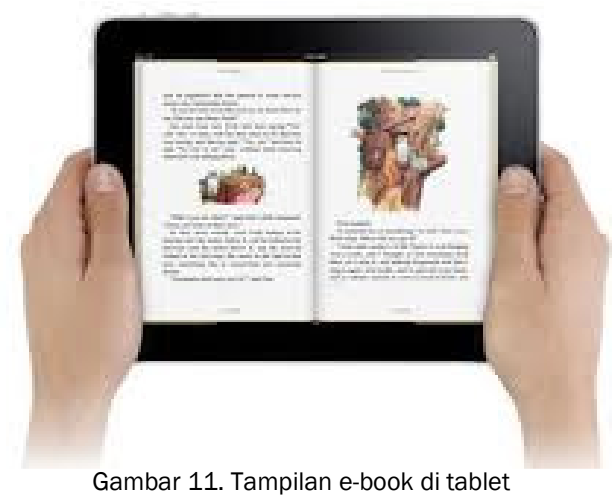

\section{PEMBAHASAN}

Pembuatan e-book menggunakan sigil sangat mudah apa lagi aplikasinnya yang Open Source, jadi semua penulis maupum pembaca dapat dengan mudah aplikasi ini.

Sesuai dengan tampilan pada gambar 1 adalah area kerja untuk membuat buku digital. Disini Materi akan dimasukan, untuk memasukan materi bisa menggunakan 2 cara yaitu mengubah document menjadi eksistensi .doc/docx. File yang bereksitensi .doc akan dirubah ke bentuk html terlebih dahulu, selanjutnya file tersebut dimasukan ke sigil seperti pada gambar 3 Untuk cara kedua menggunakan eksistensi jpeg dimana file document atau pdf akan di konfersi terlebih dahulu ke bentuk jpeg.

Untuk memulai langkah awal data atau document dimasukan satu persatu ke sigil, selanjutnya pembuatan Table of Content dimana fungsinya sama dengan daftar isi pada buku, dimana daftar isi akan di linkkan ke halaman yang sesuai dengan daftar isi, dimana nantinya pemanggilan halaman berdasarkan daftar isi bisa melalui table of content. Selain memasukan document atau jpeg, sigil mendukung import multimedia seperti video dan audio. Untuk memasukan file video atau audio cukup menempatkan cursor di tempat yang dinginkan klik kanan $>>$ insert file $>>$ other file $>>$ pilih video atau audio yang diinginkan. Format yang didukung untuk video adalah .mp4 dan webm sedangkan pada audio mendukung format .mp3 .ogg dan wav. File epub yang telah jadi bisa di buka di aplikasi readium pada google chrome dan pada Mozilla firefox bisa di buka dengan epubreader Publikasi merupakan tahapan berikutnya setelah berhasil mebuat buku digital dengan format epub.

Dengan adanya Epub lebih memudahkan pembaca untuk membaca isi e-book secara acak atau secara yang diinginkan dengan ketersediaan daftar isi seperti gambar 12.

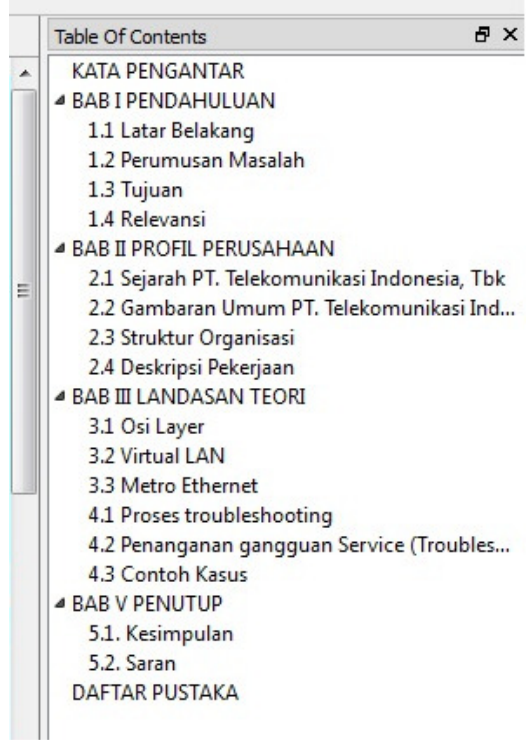

Gambar 12. Table Of Contents 


\section{KESIMPULAN}

E-book dengan format epub lebih dinamis dibandingkan dengan format yang lainnya, karena ukuran tulisan, nomor halaman, gambar dan paragraf selelu menyesuaikan dengan layar perangkat yang digunakan oleh pembaca. E-book dengan format epub ini bukan buku yang belum siap untuk di cetak melainkan memudahkan penulis untuk menerbitkannya dengan biaya yang murah serta kenyamanan pembaca dapat mengakses isi buku dimanapun menggunakan perangkat seluler dari halaman berapapun dengan adanya daftar isi, Hal tersebut membuat pembaca akan merasa seperti membaca buku cetak biasanya.

Dalam pembuatan e-book menggunakan sigil lebih baik file-nya dalam bentuk doc/docx, agar dapat diedit dan dapat membuat daftar isi dengan link persub bab, jika filenya dalam bentuk image akan mengalami kesulitan dalam pengeditan karena semua file dalam bentuk image, pegeditan harus dilakukan seperti petama pembuatan buku selain itu pada daftar isi tidak bisa membuat link persub bab melainkan per image.

\section{REFERENSI}

[1] Gardiner, Eileen and Ronald G. Musto. (2010). The Electronik Book. In Suarez, Michael Felix, and H. R. Woudhuysen. The Oxford Companion to the book: Oxford University Press, 2010, hlm. 164.

[2] Hameed, N., Cheah, Y. N., \& Rafie, M. (2010). An e-book personalization architecture with digital rights and encryption procedures. Information Technology ITSim 2010 International Symposium in.

[3] Marinai, S., Marino, E., \& Soda, G. (2011). Conversion of PDF Books in ePub Format. 2011 International Conference on Document Analysis and Recognition. IEEE. Retrieved from http://ieeexplore.ieee.org/Ipdocs/epic03/wrapper.htm?arnumber=6065357

[4] Kennedy, D. (2011). EPUB 3 : the Digital Publishing Standard is Revised and Expanded. Seybold Report, 11(16), 2-6. Retrieved from http://www.seyboldpublications.com/product-p/tsr1116.htm

[5] SEAMOLEC, [2013]. Materi Simulasi Digital, hlm. 133-160. 